\title{
TP53 codon 72 Polymorphism and bladder cancer risk: a meta-analysis and emphasis on the role of tumor or smoking status
}

\author{
Lei Zhang*, Yi Wang*, Zhiqiang Qin*, Ran Li, Rong Cong, Chengjian Ji, Xianghu Meng, Yamin Wang ${ }^{\bowtie}$, \\ Jiadong $\mathrm{Xia}^{\otimes}$, Ninghong Song \\ Department of Urology, The First Affiliated Hospital of Nanjing Medical University, Nanjing, 210009, China. \\ * These authors contributed equally to this work \\ $\square$ Corresponding authors: Jiadong Xia, Department of Urology, The First Affiliated Hospital of Nanjing Medical University, No. 300 Guangzhou Road, Nanjing, \\ 210029, China. E-mail: dongjiaxianjmu@sina.com; TEL: +08613921433817 and Yamin Wang, Department of Urology, The First Affiliated Hospital of Nanjing \\ Medical University, No. 300 Guangzhou Road, Nanjing, 210029, China. E-mail: wangyamin231@163.com; TEL: +08618262637569 \\ (c) Ivyspring International Publisher. This is an open access article distributed under the terms of the Creative Commons Attribution (CC BY-NC) license \\ (https://creativecommons.org/licenses/by-nc/4.0/). See http://ivyspring.com/terms for full terms and conditions.
}

Received: 2018.03.24; Accepted: 2018.07.27; Published: 2018.09.08

\begin{abstract}
Background: Various studies had explored the relationship between TP53 codon 72 polymorphisms and the risk of bladder cancer (BC). However, their results remained inconsistent and the definite role of smoking or tumor status associated with this polymorphism in BC cases was seldom involved. Hence, this meta-analysis was to disclose such associations.

Methods: Systematical and comprehensive retrieval of online databases PubMed, PMC, EMBASE and Web of Science were conducted to obtain eligible studies, up to May 30th, 2018. Pooled odds ratios (ORs) with $95 \%$ confidence intervals $(\mathrm{Cl})$ were utilized to assess the associations between TP53 codon 72 polymorphisms and BC susceptibilities under five genetic comparison models.

Results: Ultimately, this meta-analysis enrolled 22 applicable studies with 3,791 BC cases and 4,917 controls. Our results suggested that the variant genotypes were associated with $\mathrm{BC}$ risk in Asian subgroup (allele model: $\mathrm{OR}=1.19,95 \% \mathrm{Cl}=1.04-1.34$; dominant model: $\mathrm{OR}=1.27,95 \% \mathrm{Cl}=1.06-1.52$; homozygote model: $\mathrm{OR}=1.36,95 \% \mathrm{Cl}=1.03-1.80$ ), while negative outcomes were presented in Caucasians. In the relationship between TP53 codon 72 polymorphisms and BC tumor stage in Asian group, positive results were presented in allele model: $\mathrm{OR}=1.68,95 \% \mathrm{Cl}=1.04-2.72$; dominant model: $\mathrm{OR}=2.46,95 \% \mathrm{Cl}=1.08-5.61$; heterozygous model: $\mathrm{OR}=2.32,95 \% \mathrm{Cl}=1.04-5.14$; homozygote model: $\mathrm{OR}=2.66,95 \% \mathrm{Cl}=1.04-6.81$. However, no evidence was revealed between this polymorphism and BC tumor grade. Besides, significant associations were displayed between TP53 codon 72 polymorphism and smoking status (allele model: $\mathrm{OR}=1.40,95 \% \mathrm{Cl}=1.06-1.84$; dominant model $\mathrm{OR}=1.72,95 \% \mathrm{Cl}=1.18-2.50$; heterozygous model: $\mathrm{OR}=1.77,95 \% \mathrm{Cl}=1.19-2.64$ ).

Conclusion: Taken together, our results shed light on that TP53 codon 72 polymorphism was significantly associated with the susceptibility to $B C$ in Asians. In addition, positive associations were also revealed between this polymorphism and tumor stage/smoking status in BC cases.
\end{abstract}

Key words: TP53 codon 72; Polymorphism; Bladder cancer; Meta-analysis

\section{Introduction}

Bladder cancer $(B C)$ is the fifth most prevalent malignancy in both sexes and the $4^{\text {th }}$ in male, the $11^{\text {th }}$ in female, with an expected 81,190 new cases and 17,240 death in the United States, 2018 [1]. The incidence rates of $\mathrm{BC}$ show imparities in worldwide with the highest morbidity in Europe, Northern America, Western Asia, and Northern Africa, but the lowest morbidity in Eastern, Middle and Western 
Africa [2]. However, the etiology of $\mathrm{BC}$ remains unclear. Previous epidemiological studies verified that many risk factors significantly associated with the occurrence of BC, included tobacco smoking, exposure to certain carcinogens like aromatic amines, long-term inflammation stimulation and genetic factors [2-5]. Therein, smoking as an important risk factor, was reported to increase approximately 2 -fold to 6-fold risks suffering from BC [6]. In the past decades, various researches had been carried out to explore the roles of genetic susceptibility in the occurrence of $\mathrm{BC}$ and some susceptible genes were identified, containing tumor protein p53 (TP53) gene [7-10].

TP53 gene (p53 gene), located at 17p13, is extensively regarded as a tumor suppressor gene. As a $53 \mathrm{kDa}$ protein encoded by TP53 gene, p53 had been demonstrated to play an essential role in regulating cell cycle, cell growth, differentiation, proliferation and apoptosis [11, 12]. Besides, p53 was also involved in maintaining DNA integrality and repairing DNA damage, thus exerting powerful inhibition effect on tumorigenesis [13]. As a result, the mutation of the TP53 might result in the loss of function of p53 protein and then induce carcinogenesis [14]. Accumulating data have explored the relationship of TP53 polymorphisms with the risk of various cancers. One of these widely studied polymorphisms is a $\mathrm{G}>\mathrm{C}$ transition in codon 72 of exon 4, leading to an arginine (Arg) to proline (Pro) amino acidic substitution and generating three different genotypes (Arg/Arg, Pro/Pro and Pro/Arg) $[15,16]$.

Various cancers had been demonstrated to be significantly associated with TP53 codon 72 gene polymorphisms, including lung cancer [17], nasopharyngeal cancer [18], hepatocellular carcinoma [19], prostate cancer [20], BC [21] and so on. Nevertheless, their results remained inconsistent, and the definite role of smoking or tumor status in association with this polymorphism in BC cases was seldom involved. Therefore, we conducted an updated meta-analysis to perform a more precise assessment on the association between this polymorphism and the risk of $\mathrm{BC}$ based on all applicable case-control studies.

\section{Materials and Methods}

\section{Literature search strategy}

We comprehensively retrieved available papers associated with P53 codon 72 polymorphisms and susceptibility to BC in the online databases PubMed, PMC, EMBASE and Web of Science, published up to May 30th, 2018. The following keywords in combination with Medical Subject Headings (MeSH) terms and text words were utilized: 'p53' or 'TP53', 'codon 72 ' or 'Arg72pro' or 'R72P' or 'rs1042522' or 'exon 4', 'polymorphism' or 'mutation' or 'variant', 'bladder cancer', or 'bladder carcinoma' or 'bladder tumor'. In addition, potentially eligible articles were identified via meticulously searching from the reference lists of relevant reviews and original literature.

\section{Inclusion and exclusion criteria}

All eligible articles included in this meta-analysis must meet following criteria: (1) Used a case-control or cohort study design; (2) Evaluated the association between TP53 codon 72 polymorphism and BC risk; (3) Presented sufficient genotype data of both cases and controls to calculate the odds ratios (ORs) and 95\% confidence intervals (CIs); (4) Enrolled patients with BC confirmed by histopathological examination and controls with no history of any other malignancies. Besides, the exclusive criteria were in accordance with the follows: (1) No case-control or cohort study; (2) Duplicated or unavailable data; (3) Studies not related to TP53 codon 72 or BC.

\section{Data Extraction}

All available data from the identified studies were extracted respectively by two reviewers (L.Z and $Y . W)$ and then checked by each other. If any disagreement achieved, a third reviewer (ZQ.Q) would join in and reached a consensus. Extracted data were recorded in a predefined form including following items: first author' name, publication year, ethnicity, source of controls, genotypic method, the number of cases and controls, concrete numbers of Arg/Arg, Arg/Pro and Pro/Pro genotypes and the results of the Hardy-Weinberg equilibrium (HWE) test respectively.

\section{Statistical analysis}

HWE was assessed in the control groups based on Pearson's goodness-of-fit chi-square test ( $\chi^{2}$ test) and significant equilibrium was considered if the $P$ value was more than 0.05 . In addition, pooled ORs with $95 \%$ CIs were presented to evaluate the strength of association between TP53 codon 72 polymorphism and susceptibility to $\mathrm{BC}$, by using five different genetic comparison models: allele model (Pro vs. Arg), homozygous model (Pro/Pro vs. Arg/Arg), heterozygous model (Pro/Arg, vs. Arg/Arg) dominant model (Pro/Pro+Pro/Arg vs. Arg/Arg) and recessive model (Pro/Pro vs. Pro/Arg+Arg/Arg). The heterogeneity among these papers was tested by Cochrane Q test and Higgins $\mathrm{I}^{2}$ statistic. Accordingly, the fixed effect model (a Mantel-Haenszel method) was applied if the heterogeneity was acceptable $\left(I^{2}<50 \%\right.$ or $\left.P>0.10\right)$ and 
the random effect model was performed (a DerSimonian-Laird method) if the heterogeneity was unwelcome $\left(I^{2}>50 \%\right.$ or $\left.P<0.10\right)$. Although the random effect model was one way to manage heterogeneity among studies, it could not explain the source of heterogeneity. Hence, subgroup analysis was further utilized to minimize heterogeneity to obtain more credible evidence. Moreover, sensitivity analysis was adopted to determine the stability and reliability of the results by recounting the pooled ORs via consecutively excluding each study once a time. Furthermore, Begg's funnel plots and Egger's linear regression test were used to check out the publication bias among all studies, and a significantly bias was considered when the $P$ value was less than 0.05 . STATA 12.0 software (StateCorporation, College Station, TX, USA) was used to conduct statistical analysis.

\section{Results}

\section{Studies characteristics}

A total of 551 potentially available studies were initially collected from a primary literature retrieval from PubMed, PMC, EMBASE, Web of Science and other sources. Based on above-mentioned inclusion and exclusion criteria, 22 studies were ultimately included in this meta-analysis for further assessment [21-42]. Detailed literature searching and screening steps were shown in Figure 1. Generally, 3,791 patients with BC and 4,917 controls were involved in this meta-analysis to evaluate the association between
TP53 codon 72 polymorphisms and BC risk, as well as the role of tumor status or smoking status in association with this mutation. The population among these studies was comprised of Asian, Caucasians and Africans. Meanwhile, main characteristics of eligible studies were presented in Table 1 and Table 2.

\section{Association between TP53 codon 72 polymorphisms and $\mathrm{BC}$ risk}

Generally, the pooled ORs with 95\% CIs were calculated to evaluate the relationship between TP53 codon 72 polymorphisms and the risk of $\mathrm{BC}$, according to five genetic comparison models. The main results of this meta-analysis were detailed in Table 3, containing overall analysis and stratified analysis by ethnicity. The overall analysis showed no remarkable results under five genetic models: allele model (OR=1.07, 95\% CI=0.95-1.20), dominant model (OR=1.08, 95\% CI=0.91-1.27), heterozygous model (OR=1.06, 95\% CI=0.89-1.27), homozygous model $(\mathrm{OR}=1.15,95 \% \quad \mathrm{CI}=0.91-1.46)$ and recessive model (OR=1.10, 95\% CI=0.88-1.36) (Figure 2). However, significant associations were revealed in Asian group, when stratified by ethnicity: allele model (OR=1.19, 95\% CI=1.06-1.34), dominant model (OR=1.27, 95\% $\mathrm{CI}=1.06-1.52)$, homozygous model (OR=1.36, 95\% $\mathrm{CI}=1.03-1.80)$. Nevertheless, no positive results were presented in Caucasians. These results indicated that TP53 codon polymorphism was an ethnicity related factor relating to $\mathrm{BC}$ susceptibility.

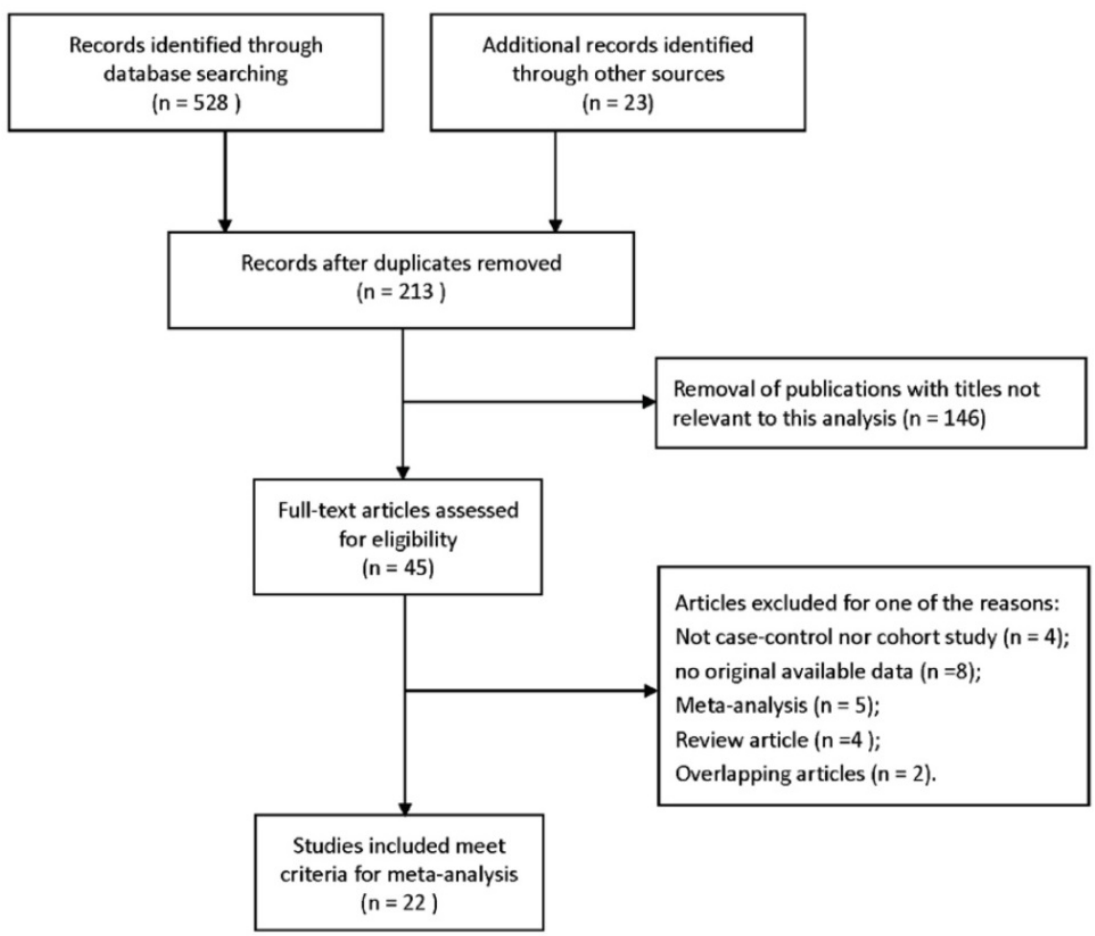


Table 1: Main characteristics for the included studies of the association between TP53 codon 72 polymorphisms and bladder cancer

\begin{tabular}{|c|c|c|c|c|c|c|c|c|c|c|c|c|c|}
\hline \multirow[t]{2}{*}{ Year } & \multirow[t]{2}{*}{ Author } & \multirow[t]{2}{*}{ Ethnicity } & \multirow[t]{2}{*}{ SOC } & \multirow[t]{2}{*}{ Genotyping } & \multirow[t]{2}{*}{ Case } & \multirow[t]{2}{*}{ Control } & \multicolumn{3}{|c|}{ Case (n) } & \multicolumn{3}{|c|}{ Control(n) } & \multirow[t]{2}{*}{ HWE } \\
\hline & & & & & & & $\overline{\mathrm{AA}}$ & $\mathrm{AP}$ & PP & AA & $\mathrm{AP}$ & PP & \\
\hline 2017 & Lin & Asian & $\mathrm{HB}$ & RT-PCR & 46 & 188 & 10 & 23 & 13 & 31 & 100 & 57 & 0.246 \\
\hline 2017 & Elhawary & Asian & $\mathrm{HB}$ & RT-PCR & 52 & 104 & 14 & 22 & 16 & 28 & 60 & 16 & 0.804 \\
\hline 2017 & Avirmed & Asian & $\mathrm{HB}$ & PCR & 63 & 79 & 35 & 20 & 8 & 37 & 23 & 19 & 0.001 \\
\hline 2015 & Hosen & Asian & HB & PCR-RFLP & 102 & 140 & 22 & 45 & 35 & 41 & 78 & 21 & 0.104 \\
\hline 2014 & Pineda & Caucasian & HB & TaqMan & 1032 & 1100 & 588 & 372 & 72 & 628 & 388 & 84 & 0.028 \\
\hline 2013 & Lin & Asian & HB & PCR-RFLP & 199 & 140 & 50 & 102 & 47 & 36 & 86 & 18 & 0.003 \\
\hline 2012 & Lin & Asian & PB & PCR-RFLP & 94 & 142 & 16 & 55 & 23 & 48 & 68 & 26 & 0.824 \\
\hline 2011 & Lin & Asian & PB & PCR-RFLP & 127 & 427 & 27 & 84 & 16 & 125 & 228 & 74 & 0.085 \\
\hline 2011 & Eduardo & Caucasian & $\mathrm{PB}$ & PCR-RFLP & 94 & 159 & 64 & 24 & 6 & 90 & 60 & 9 & 0.808 \\
\hline 2011 & Srivastava & Asian & $\mathrm{HB}$ & PCR-RFLP & 200 & 265 & 103 & 93 & 4 & 141 & 106 & 18 & 0.749 \\
\hline 2011 & Zhang & Asian & HB & PCR-RFLP & 120 & 120 & 37 & 59 & 24 & 55 & 47 & 18 & 0.141 \\
\hline 2010 & Pandith & Asian & $\mathrm{HB}$ & PCR-RFLP & 108 & 138 & 22 & 68 & 18 & 59 & 53 & 26 & 0.030 \\
\hline 2008 & $\mathrm{Ye}$ & Caucasian & HB & PCR-RFLP & 615 & 598 & 390 & 186 & 39 & 390 & 156 & 52 & $<0.000$ \\
\hline 2008 & Horikawa & Asian & HB & PCR-CTPP & 227 & 267 & 73 & 118 & 36 & 93 & 136 & 38 & 0.297 \\
\hline 2008 & Chung & Asian & HB & PCR-RFLP & 170 & 402 & 47 & 87 & 36 & 134 & 194 & 74 & 0.797 \\
\hline 2003 & Kuroda & Asian & $\mathrm{HB}$ & PCR-RFLP & 112 & 175 & 38 & 38 & 36 & 63 & 77 & 35 & 0.200 \\
\hline 2003 & Mabrouk & Africa & PB & PCR & 47 & 34 & 21 & 23 & 3 & 13 & 19 & 2 & 0.254 \\
\hline 2002 & Soulitzis & Caucasian & PB & PCR & 50 & 99 & 30 & 18 & 2 & 24 & 64 & 11 & 0.002 \\
\hline 2001 & Toruner & Caucasian & PB & PCR & 121 & 114 & 43 & 57 & 21 & 42 & 55 & 17 & 0.884 \\
\hline 2000 & Brio & Caucasian & PB & PCR-RFLP & 50 & 145 & 28 & 18 & 4 & 71 & 54 & 20 & 0.071 \\
\hline 2000 & Chen & Asian & HB & PCR & 58 & 59 & 26 & 25 & 7 & 25 & 26 & 8 & 0.765 \\
\hline 1995 & $\mathrm{Wu}$ & Asian & HB & PCR-RFLP & 151 & 56 & 69 & 60 & 22 & 26 & 24 & 6 & 0.896 \\
\hline
\end{tabular}

SOC: Source of controls; PB: Population-based controls; HB: Hospital-based controls; AA: ArgArg; AP: ArgPro; PP:ProPro; HWE: Hardy-Weinberg equilibrium.

Table 2: Main characteristics of individual studies to explore the role of smoking or tumor status associated with TP53 codon 72 polymorphisms in bladder cancer

\begin{tabular}{|c|c|c|c|c|c|c|c|c|}
\hline \multicolumn{3}{|c|}{ Tumor stage } & \multicolumn{6}{|c|}{ Superficial pTis, pTa, pT1 Invasive $\geq$ pT2 } \\
\hline Year & Surname & Ethnicity & AA & $\mathrm{AP}$ & PP & AA & $\mathrm{AP}$ & $\mathrm{PP}$ \\
\hline 2015 & Hosen & Asian & 15 & 34 & 26 & 7 & 11 & 9 \\
\hline 2011 & Eduardo & Caucasian & 38 & 15 & 5 & 26 & 9 & 1 \\
\hline 2011 & Zhang & Asian & 33 & 39 & 13 & 4 & 20 & 11 \\
\hline 2010 & Pandith & Asian & 16 & 26 & 7 & 6 & 43 & 10 \\
\hline 2008 & Horikawa & Asian & 59 & 91 & 26 & 14 & 27 & 10 \\
\hline 2002 & Soulitzis & Caucasian & 26 & 16 & 2 & 4 & 2 & 0 \\
\hline 2001 & Toruner & Caucasian & 30 & 45 & 13 & 13 & 12 & 8 \\
\hline 2000 & Chen & Asian & 24 & 9 & 1 & 2 & 16 & 6 \\
\hline 1995 & $\mathrm{Wu}$ & Asian & 36 & 29 & 10 & 28 & 25 & 8 \\
\hline \multicolumn{3}{|c|}{ Tumor grade } & \multicolumn{3}{|c|}{$\mathrm{G} 1+\mathrm{G} 2$} & \multicolumn{3}{|l|}{$\geq \mathrm{G} 3$} \\
\hline Year & Surname & Ethnicity & AA & $\mathrm{AP}$ & PP & AA & $\mathrm{AP}$ & PP \\
\hline 2015 & Hosen & Asian & 16 & 26 & 22 & 6 & 19 & 13 \\
\hline 2010 & Pandith & Asian & 17 & 32 & 3 & 6 & 40 & 10 \\
\hline 2008 & Horikawa & Asian & 38 & 66 & 16 & 35 & 52 & 20 \\
\hline 2002 & Soulitzis & Caucasian & 23 & 14 & 2 & 7 & 4 & 0 \\
\hline \multirow[t]{2}{*}{1995} & $\mathrm{Wu}$ & Asian & 38 & 33 & 13 & 26 & 21 & 6 \\
\hline & & & \multicolumn{3}{|c|}{ Smoking } & \multicolumn{3}{|c|}{ Non-smoking } \\
\hline Year & Surname & Ethnicity & $\mathrm{AA}$ & $\mathrm{AP}$ & PP & AA & $\mathrm{AP}$ & $\mathrm{PP}$ \\
\hline 2010 & Pandith & Asian & 16 & 58 & 16 & 6 & 10 & 2 \\
\hline 2003 & Kuroda & Asian & 29 & 32 & 32 & 9 & 6 & 4 \\
\hline 2001 & Toruner & Caucasian & 25 & 38 & 17 & 12 & 15 & 4 \\
\hline 1995 & $\mathrm{Wu}$ & Asian & 31 & 36 & 8 & 28 & 18 & 10 \\
\hline
\end{tabular}

Tumor status associated with TP53 codon 72 polymorphisms in BC cases

During the process of retrieving eligible articles, we found that a total of 9 studies had described the relationship between TP53 codon 72 genotypes and tumor stage/grade in the case of BC. Hence, we conducted an additional analysis to explore the role of this polymorphism in patients with different tumor stage or grade (Table 3 ). As a result, no positive finding was shown in the general population. In the relationship between TP53 codon 72 polymorphisms and $\mathrm{BC}$ tumor stage in Asian group, positive results were presented in allele model: $\mathrm{OR}=1.68,95 \%$ $\mathrm{CI}=1.04-2.72$; dominant model: $\mathrm{OR}=2.46$, 95\% $\mathrm{CI}=1.08-5.61$; heterozygous model: $\mathrm{OR}=2.32$, 95\% $\mathrm{CI}=1.04-5.14$; homozygote model: $\mathrm{OR}=2.66$, 95\% $\mathrm{CI}=1.04-6.81$ (Figure 3). However, no association was found between different tumor grade $(\mathrm{G} 3+\mathrm{G} 4$ vs. G1+G2) and this polymorphism (allele model: $\mathrm{OR}=1.16$, 95\% CI $=0.86-1.58$; dominant model $\mathrm{OR}=1.29$, 95\% $\mathrm{CI}=0.75-2.23$; heterozygous model: $\mathrm{OR}=1.25$, 95\% $\mathrm{CI}=0.76-2.07$; homozygote model: $\mathrm{OR}=1.55,95 \%$ $\mathrm{CI}=0.70-3.41$; recessive model: $\mathrm{OR}=1.25, \quad 95 \%$ $\mathrm{CI}=0.78-1.99$ ) (Figure 4).

\section{Smoking status associated with TP53 codon 72 polymorphisms in BC cases}

Smoking, as a well-known risk factor of BC susceptibility, was studied among 5 studies to shed light on that whether or not it could lead to the $G>C$ mutation. Accordingly, an additional analysis was conducted to evaluate the relationship between them. As displayed in Figure 5, significant associations were displayed between TP53 codon 72 polymorphism and smoking status (allele model: OR=1.40, 95\% $\mathrm{CI}=1.06-1.84$; dominant model $\mathrm{OR}=1.72$, 95\% $\mathrm{CI}=1.18-2.50$; heterozygous model: $\mathrm{OR}=1.77$, 95\% $\mathrm{CI}=1.19-2.64)$. The concrete quantitative values were also presented in Table 3 .

\section{Sensitivity analysis}

Sensitivity analysis was conducted to access the stability of results by deleting one single study each time, to reflect the impact of the individual to overall. The sensitivity analysis for the results of TP53 codon 72 genetic polymorphisms and $\mathrm{BC}$ risk indicated that 
no single study significantly influenced the pooled OR and 95\% CIs. Namely, our results were robust (Figure 6).

\section{Publication bias}

The Begg's funnel plot and Egger's test were applied to assess the publication bias in this meta-analysis. According to the results of them, $P$ values were all above 0.05 in all models, indicating no significant bias were identified. In other words, our results were reliable based on the available articles (Figure 7).

Table 3: Meta-analysis results of individual studies included in this meta-analysis

\begin{tabular}{|c|c|c|c|c|c|c|c|c|c|c|c|c|c|c|c|c|}
\hline \multirow[t]{2}{*}{ Variables } & \multirow{2}{*}{$\begin{array}{l}\text { No. of } \\
\text { studies }\end{array}$} & \multicolumn{3}{|l|}{ Allele model } & \multicolumn{3}{|c|}{ Dominant model } & \multicolumn{3}{|c|}{ Heterozygous model } & \multicolumn{3}{|c|}{ Homozygous model } & \multicolumn{3}{|c|}{ Recessive model } \\
\hline & & $\mathrm{OR}(95 \% \mathrm{CI})$ & $\begin{array}{l}\mathrm{P} \\
\text { value }\end{array}$ & $\mathrm{I}^{2}(\%)$ & OR(95\%CI) & $\begin{array}{l}\mathrm{P} \\
\text { value }\end{array}$ & $\mathrm{I}^{2}(\%)$ & $\mathrm{OR}(95 \% \mathrm{CI})$ & $\begin{array}{l}P \\
\text { value }\end{array}$ & $\mathrm{I}^{2}(\%)$ & $\mathrm{OR}(95 \% \mathrm{CI})$ & $\begin{array}{l}\mathrm{P} \\
\text { value }\end{array}$ & $\mathrm{I}^{2}(\%)$ & $\mathrm{OR}(95 \% \mathrm{CI})$ & $\begin{array}{l}\mathrm{P} \\
\text { value }\end{array}$ & $\mathrm{I}^{2}(\%)$ \\
\hline Total & 22 & $1.07(0.95,1.20)$ & 0.000 & $58.4 \%$ & $1.08(0.91,1.27)$ & 0.000 & $62 \%$ & $1.06(0.89,1.27)$ & 0.000 & $62.2 \%$ & $1.15(0.91,1.46)$ & 0.002 & $53.2 \%$ & $1.10(0.88,1.36)$ & 0.001 & $54.3 \%$ \\
\hline \multicolumn{17}{|l|}{ Ethnicity } \\
\hline Asian & 15 & $1.19(1.06,1.34)$ & 0.057 & $39.7 \%$ & $1.27(1.06,1.52)$ & 0.042 & $42.4 \%$ & $1.23(0.99,1.51)$ & 0.013 & $50.3 \%$ & $1.36(1.03,1.80)$ & 0.021 & $47.6 \%$ & $1.21(0.92,1.59)$ & 0.002 & $59.1 \%$ \\
\hline Caucasian & 6 & $0.84(0.68,1.04)$ & 0.012 & $67.5 \%$ & $0.78(0.56,1.07)$ & 0.001 & $76.1 \%$ & $0.79(0.56,1.12)$ & 0.001 & $76.3 \%$ & $0.81(0.59,1.11)$ & 0.240 & $25.9 \%$ & $0.84(0.67,1.06)$ & 0.544 & $0.0 \%$ \\
\hline Africa & 1 & $0.87(0.45,1.70)$ & - & - & $0.77(0.31,1.88)$ & & & $0.75(0.30,1.88)$ & - & - & $0.93(0.14,6.32)$ & - & - & $1.09(0.17,6.91)$ & - & - \\
\hline \multicolumn{17}{|l|}{ Tumor stage } \\
\hline$\geq \mathrm{pT} 2$ vs $<\mathrm{pT} 2$ & 9 & $1.39(0.94,2.05)$ & 0.001 & $70.1 \%$ & $\begin{array}{l}1.66(0.90, \\
3.08)\end{array}$ & 0.000 & $71.7 \%$ & $1.60(0.87,2.94)$ & 0.002 & $67.6 \%$ & $1.94(0.93,4.05)$ & 0.013 & $58.8 \%$ & $1.43(0.98,2.10)$ & 0.396 & $4.7 \%$ \\
\hline \multicolumn{17}{|l|}{ Ethnicity } \\
\hline Asian & 6 & $1.68(1.04,2.71)$ & 0.001 & $76.5 \%$ & $2.46(1.08,5.61)$ & 0.000 & $77.5 \%$ & $2.32(1.04,5.14)$ & 0.002 & $73.4 \%$ & $2.66(1.04,6.81)$ & 0.006 & $69.4 \%$ & $1.46(0.92,2.33)$ & 0.287 & $19.3 \%$ \\
\hline Caucasian & 3 & $0.89(0.57,1.39)$ & 0.556 & $0.00 \%$ & $0.76(0.43,1.36)$ & 0.980 & $0.0 \%$ & $0.74(0.40,1.37)$ & 0.867 & $0.0 \%$ & $1.05(0.41,2.68)$ & 0.452 & $0.0 \%$ & $1.28(0.48,3.39)$ & 0.337 & $8.0 \%$ \\
\hline \multicolumn{17}{|l|}{ Tumor grade } \\
\hline$\geq \mathrm{G} 3$ vs $\mathrm{G} 1+\mathrm{G} 2$ & 5 & $1.16(0.86,1.58)$ & 0.195 & $33.9 \%$ & $\begin{array}{l}1.29(0.75 \\
2.23)\end{array}$ & 0.100 & $48.6 \%$ & $1.25(0.76,2.07)$ & 0.184 & $35.6 \%$ & $1.55(0.70,3.41)$ & 0.110 & $47.0 \%$ & $1.25(0.78,1.99)$ & 0.379 & $4.9 \%$ \\
\hline \multicolumn{17}{|l|}{ Ethnicity } \\
\hline Asian & 4 & $1.20(0.86,1.68)$ & 0.139 & $45.4 \%$ & $1.40(0.75,2.62)$ & 0.057 & $60.0 \%$ & $1.33(0.73,2.41)$ & 0.106 & $51.0 \%$ & $1.66(0.69,3.96)$ & 0.064 & $58.7 \%$ & $1.27(0.74,2.19)$ & 0.258 & $25.7 \%$ \\
\hline Caucasian & 1 & $0.74(0.22,2.47)$ & - & - & $0.82(0.21,3.28)$ & - & - & $0.94(0.23,3.79)$ & - & - & $0.63(0.03,14.56)$ & - & - & $0.65(0.03,14.58)$ & - & - \\
\hline \multicolumn{17}{|l|}{$\begin{array}{l}\text { Smoking } \\
\text { status }\end{array}$} \\
\hline $\begin{array}{l}\text { No-smoking } \\
\text { vs smoking }\end{array}$ & 5 & $1.40(1.06,1.84)$ & 0.706 & $0.0 \%$ & $1.72(1.18,2.50)$ & 0.897 & $0.0 \%$ & $1.77(1.19,2.64)$ & 0.909 & $0.0 \%$ & $1.53(0.83,2.79)$ & 0.501 & $0.0 \%$ & $1.21(0.70,2.11)$ & 0.425 & $0.0 \%$ \\
\hline
\end{tabular}

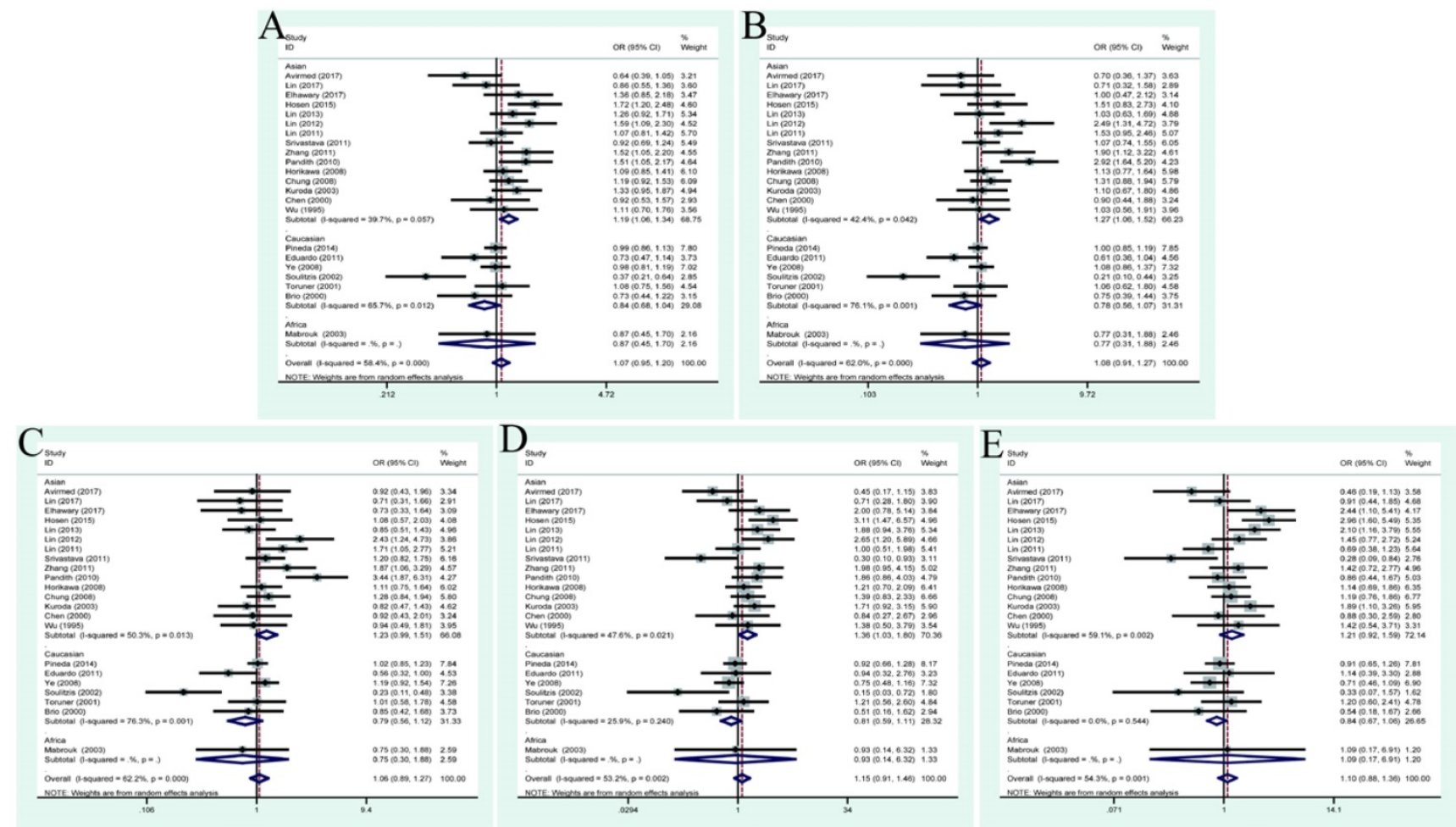

Figure 2: Forest plots of association between TP53 codon 72 polymorphisms and bladder cancer risk. (A)allele model; (B) dominant model; (C) heterozygote model; (D) homozygote model; (E)recessive model. 

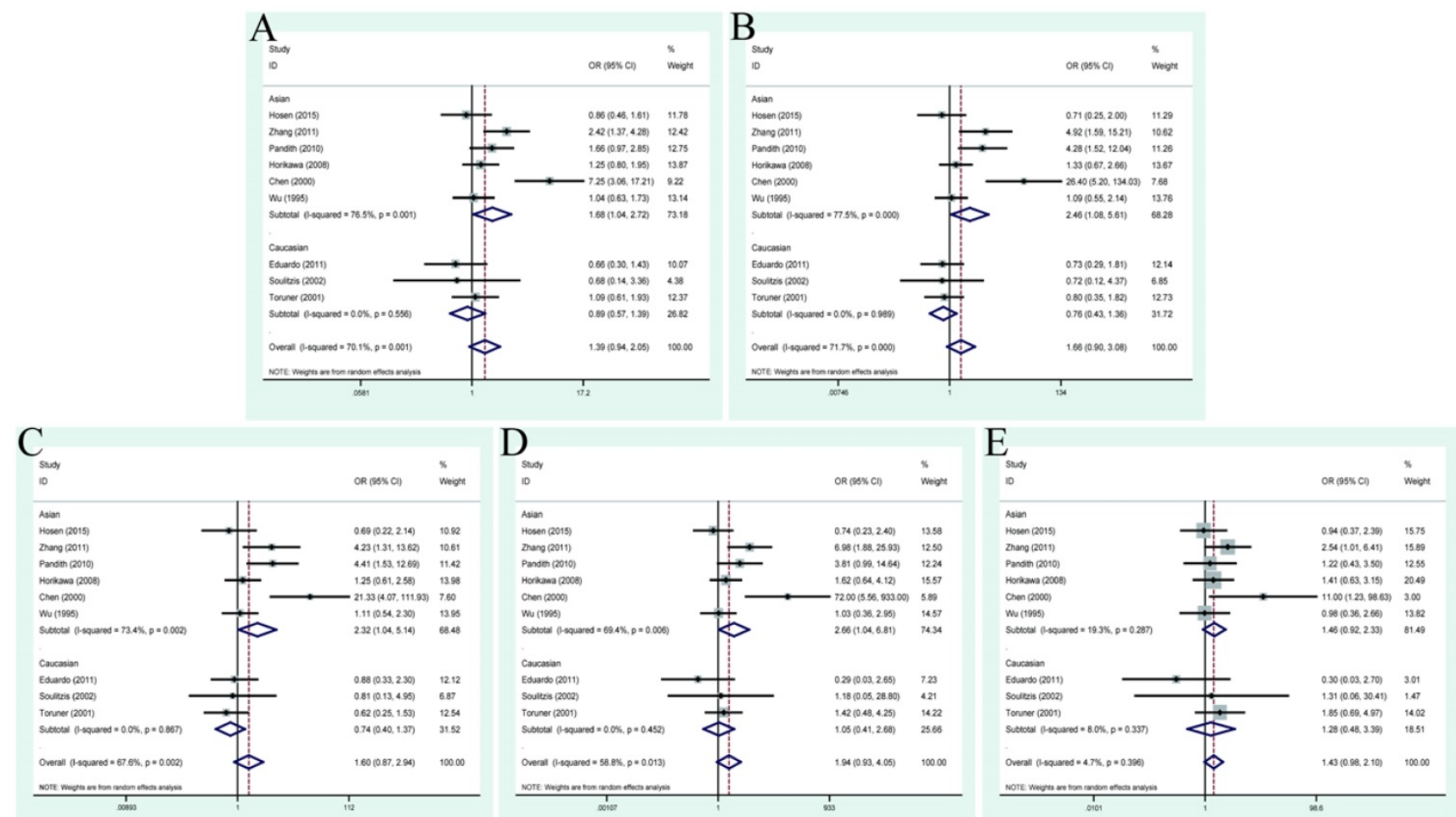

Figure 3: Forest plots of tumor stage associated with TP53 codon 72 polymorphisms. (A)allele model; (B) dominant model; (C) heterozygote model; (D) homozygote model; (E)recessive model.
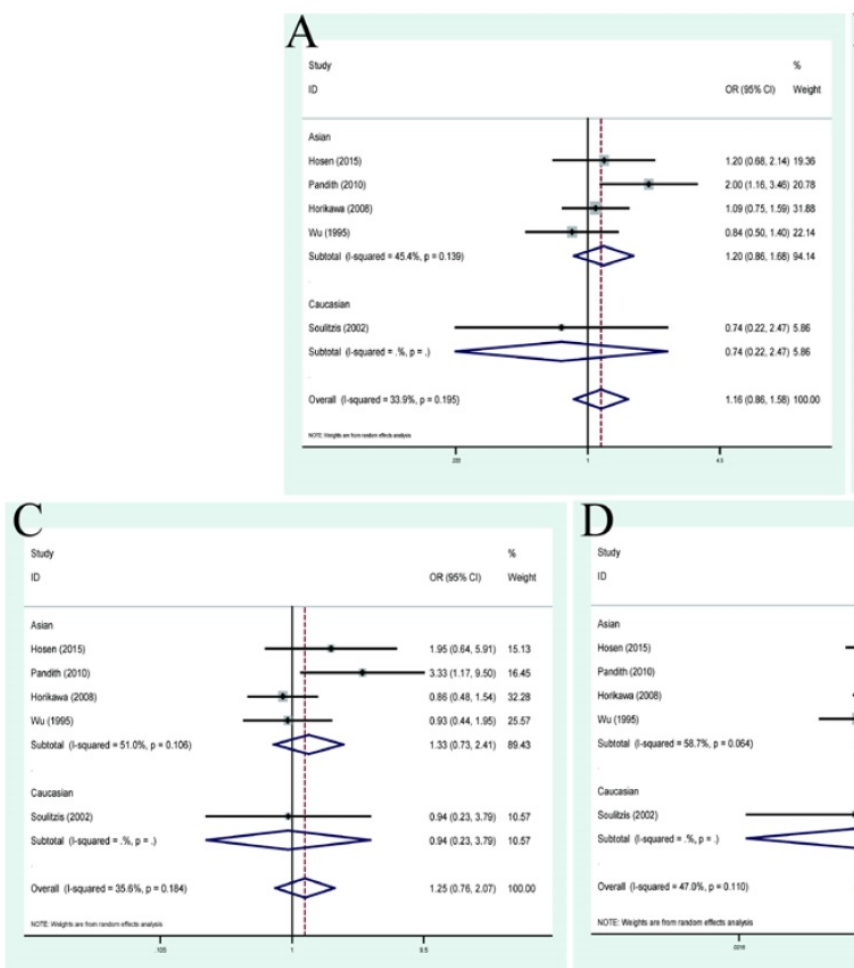
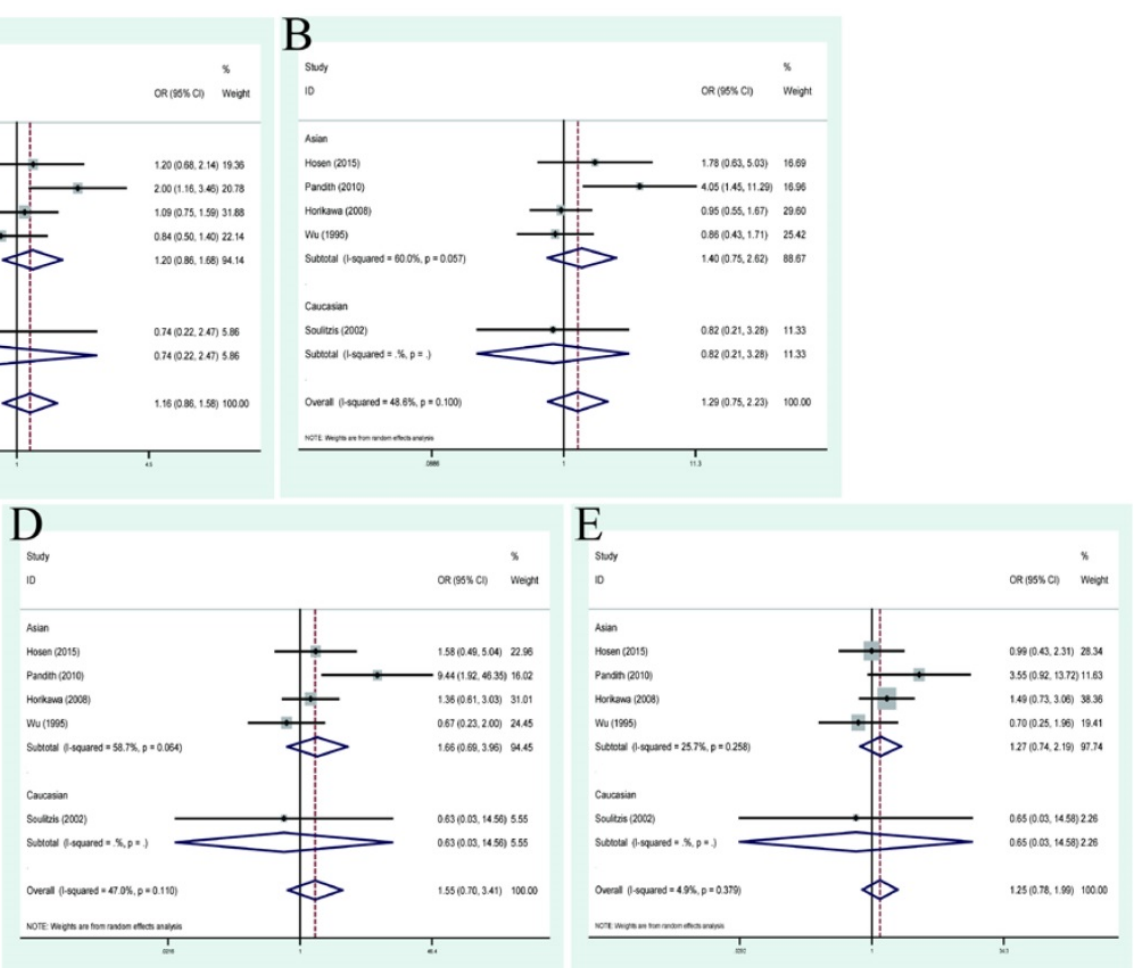

Figure 4: Forest plots of tumor grade associated with TP53 codon 72 polymorphisms. (A)allele model; (B) dominant model; (C) heterozygote model; (D) homozygote model; (E)recessive model. 

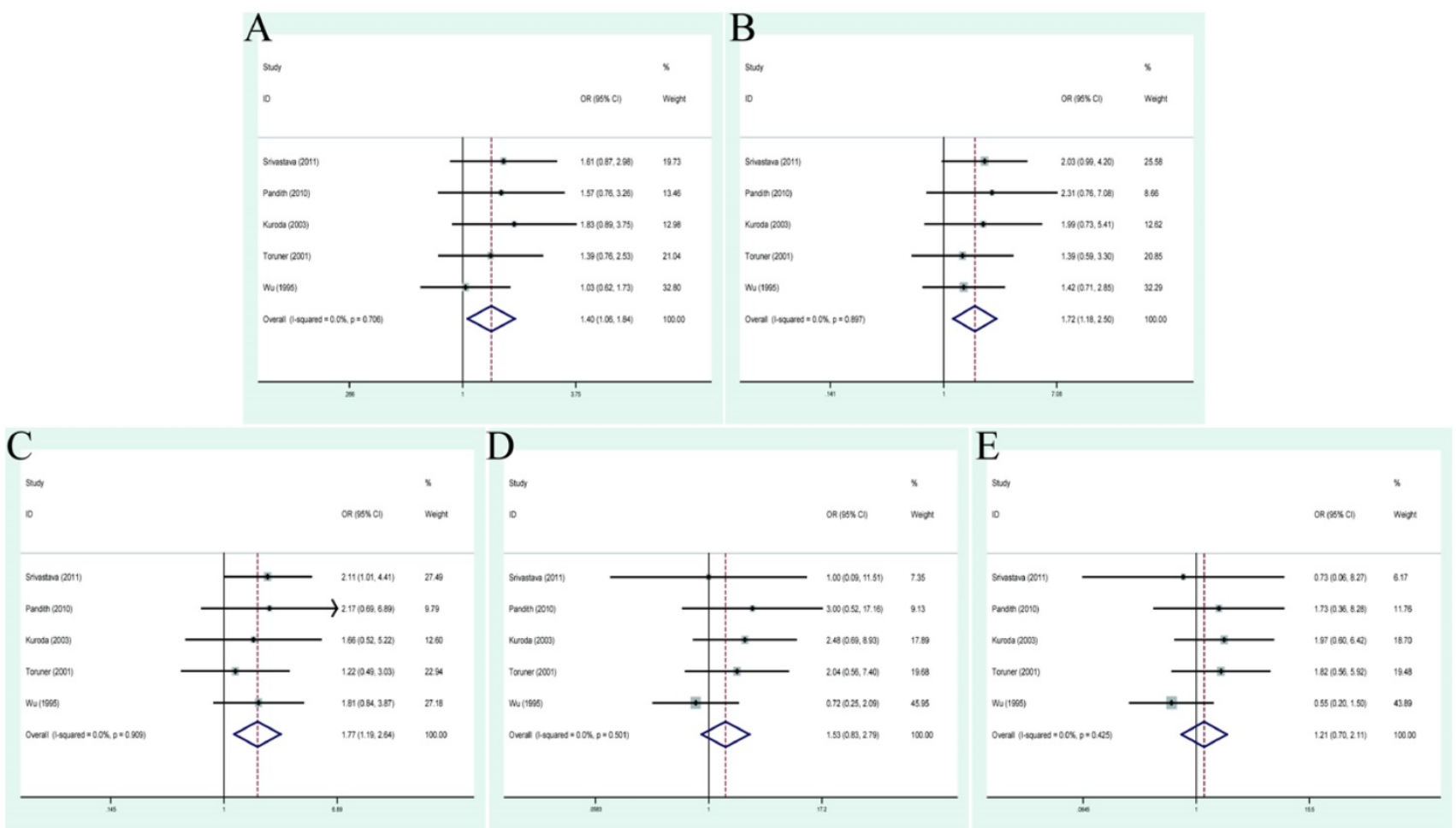

Figure 5: Forest plots of smoking status associated with TP53 codon 72 polymorphisms. (A)allele model; (B) dominant model; (C) heterozygote model; (D) homozygote model; (E)recessive model.

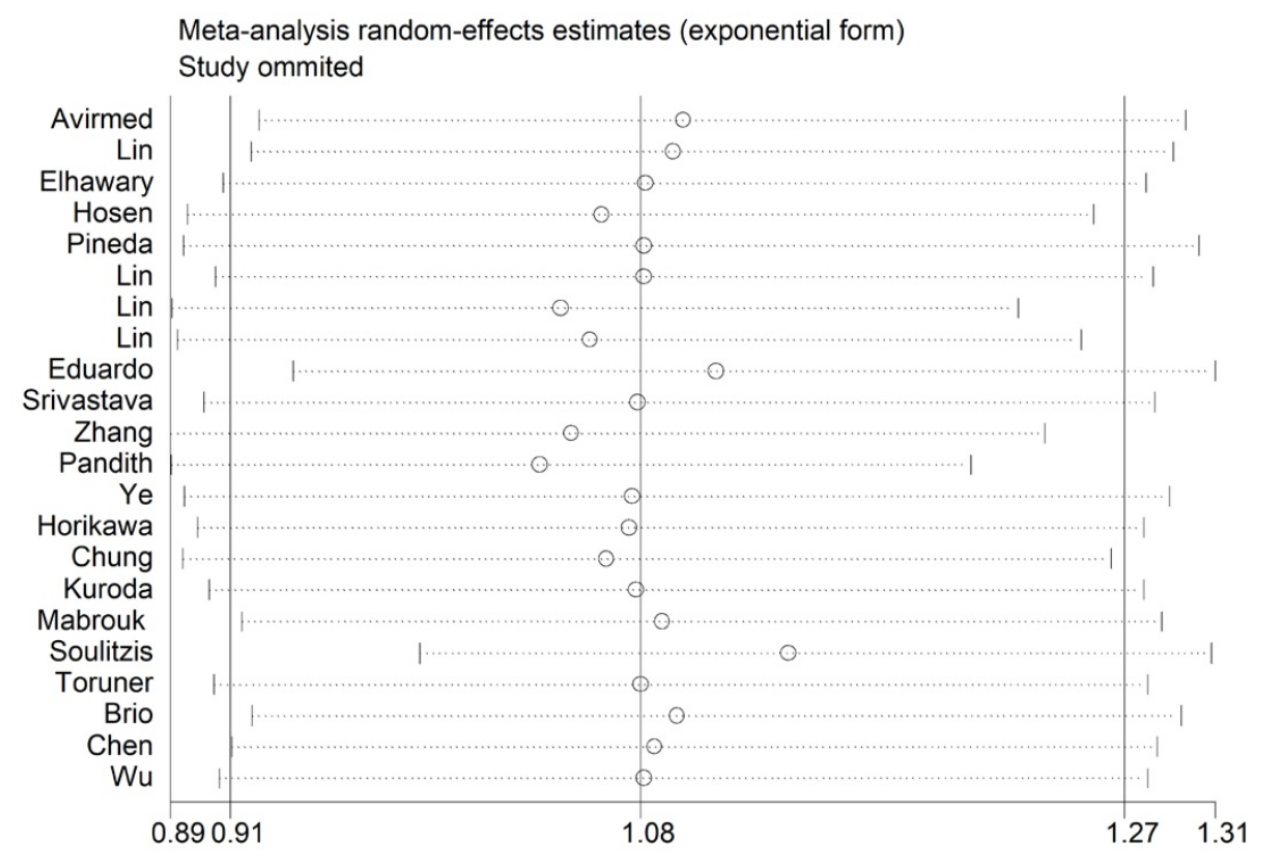

Figure 6: Sensitivity analysis of each included study in dominant model.

\section{Discussion}

Genetic susceptibility has been generally recognized as one of the important risk factors of $B C$ [43]. TP53 as a well-known tumor suppressor gene, has been demonstrated to play a vital role in regulating cell growth and maintaining DNA integrity [13]. TP53 Codon 72 as a Single Nucleotide
Polymorphism (SNP) in exon 4, was found to be able to disturb the normal function of p53 protein in various aspects and induce tumorigenesis [44]. Accumulating data had been carried out to explore this polymorphism and BC susceptibility. However, their results remained inconsistent. Although previous meta-analysis had revealed a significant association in Asians [10, 45], this perspective was 


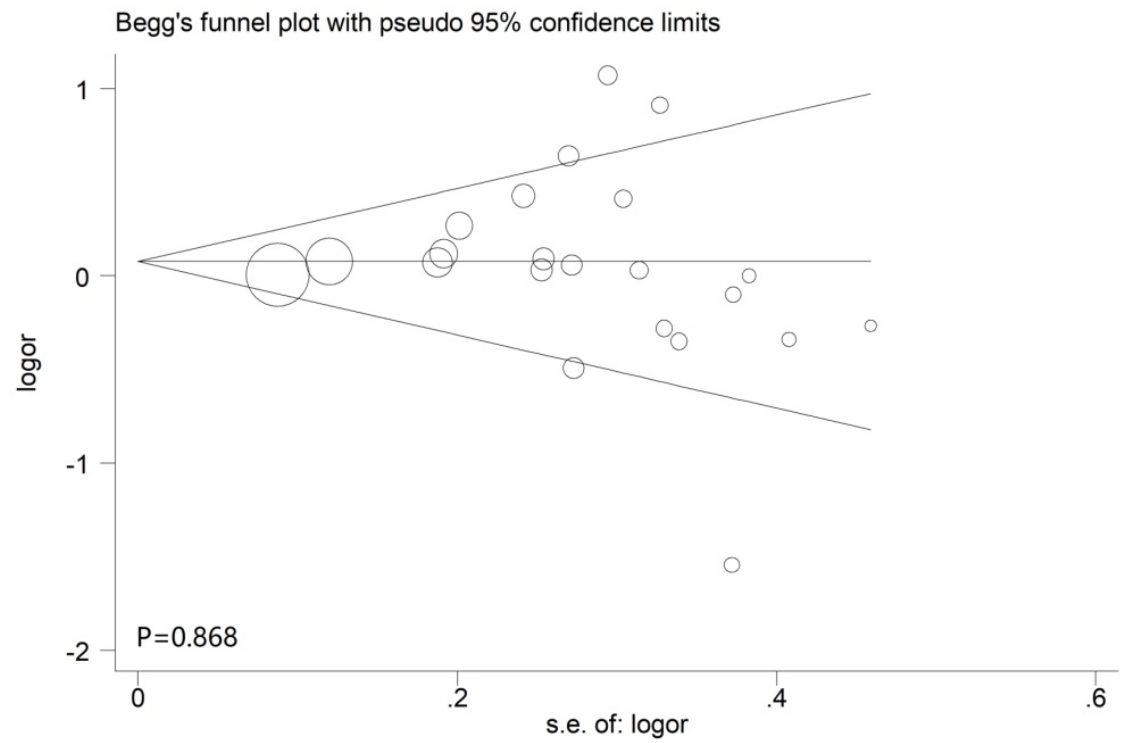

Figure 7: Begg's funnel plots of the publication bias in dominant model.
What's more, it was the first time for us to investigate whether or not this polymorphisms was correlated with the tumor status and smoking status in BC cases. Hosen et al. found a difference of TP53 codon 72 genotypes distribution among people with different tumor stage and grade [25]. Besides, Kuroda et al. discovered that the Pro72 genotype was more common in ever-smoking population [36]. Thus, we decided to explore the definite role of this polymorphism in tumor stage/grade and smoking status.

When it comes to the relationship between TP53 codon 72 genotypes and tumor status in case of $\mathrm{BC}$, Basu et al. proved that the

lack of persuasion due to limited enrolled studies and deficient genetic comparison model. In addition, the definite role of this polymorphism in different tumor stage or grade of BC had not been fully clarified. What's more, as a vital risk factor of $\mathrm{BC}$, whether long-term exposure to cigarette can lead to the $\mathrm{G}>\mathrm{C}$ mutation of TP53 codon 72 remained to be defined. Hence, this updated meta-analysis was performed with the larger sample size to evaluate the mutual association between this polymorphism and BC susceptibility and to clarify the above-mentioned doubts.

Our findings verified the relationship between TP53 codon 72 and BC risk in Asians but not Caucasians. It indicated that this polymorphism might be an ethnicity related factor of susceptibility to BC. From another point of view, it seemed that different ethnic groups with multiple genetic backgrounds might have different gene polymorphism risk in the occurrence and development of BC. Sjalander et al. found that the genotype of p53 codon 72 was differentially distributed in different ethnic populations, originating from different regions of the world. The Arg allele was more common among people in northern parts than southern [46]. In addition, Shi et al. found that this polymorphism was closely correlated with environmental climate [47]. It has been confirmed that the TP53 Pro72 isoform was less active in regulating cellular function than TP53 Arg72 [48]. Based on our results, Pro allele was less common in Asians, compared with Arg allele. As a result, we speculated that TP53 Pro 72 could not exert normal tumor suppressor function in Asians, while TP53 Arg72 could maintain the activity. presence of Pro72 could enhance the invasive and metastatic properties of mutant p53 by regulating the reactions with PGC-1a, one important regulator of mitochondrial biogenesis and oxidative phosphorylation [49]. Therefore, we retrieved papers and kept an eye on related articles that researched the difference of this polymorphism among BC patients with different tumor stages or grade. Ultimately, 9 articles were found to describe the association of TP53 codon 72 polymorphism with invasive $\mathrm{BC}(\geq \mathrm{pT} 2)$ or superficial cancer $(<\mathrm{pT} 2)$. Besides, 5 relevant articles compared the different TP53 genotypes distribution between high grade tumor $(\geq \mathrm{G} 3)$ and low grade tumor $(\mathrm{G} 1+\mathrm{G} 2)$. Based on our results, patients with invasive bladder cancer $(\geq \mathrm{pT} 2)$ were more likely having the Pro genotype than those with superficial cancer $(<\mathrm{pT} 2)$ in Asian groups. Nevertheless, no significant difference was found in this polymorphism among patients with different tumor grade. Therefore, we thought that the Pro in Asians might lead to escalating invasion of $\mathrm{BC}$.

Saikia et al. shed light on that the potential effect of TP53 codon 72 polymorphisms on the risk of cancer via interacting synergistically with environmental factors and lifestyles like alcohol drinking and tobacco smoking [50]. Smoking is a defined risk factor of BC, but it was unknown if it could lead to a mutation on TP53 codon 72. Although no specialized study was found focusing on the differential distribution of TP53 codon 72 genotypes in smoking or non-smoking groups, we unexpectedly found that some included studies investigated it in BC cases. Thus, we conducted this extra analysis to explore the potential relationship of smoking status and this polymorphism. As our results shown, there was a 
significant difference of this polymorphism between smoking or non-smoking groups. Accordingly, we hypothesized that long-term exposure to cigarette could lead to an Arg to Pro transition. Nevertheless, it remained to be established by a more population-based TP53 codon 72 genetic screening.

Recently, a large number of studies have investigated the association between TP53 codon 72 polymorphisms and $\mathrm{BC}$, including mechanism research, cancer susceptibility and prognosis [22, 44, 51]. As reported by Kung, increased growth arrest and decreased apoptosis were found in R72 cells compared with P72 cells. Because this SNP could influence the phosphorylation of p53, the transactivation of the key p53 target (p21), the activation of the kinase AMPK and the change of cell metabolism [52]. Finally, the dysfunction of p53 led to elevated risk of carcinogenesis. Except for cancer susceptibility, this polymorphism was also extensively studied as a prognostic factor in various cancers. Zha et al. found that Pro/Pro genotypes correlated with poor prognosis in advanced gastric cancer patients treated with paclitaxel plus capecitabine chemotherapy, while Kumari et al. considered Pro/Pro as a better predictor in the survival of lung cancer patients treated with platinum-based chemotherapy $[53,54]$. Thus, the role of tp53 codon 72 in cancer prognosis remained unclear, and whether or not it could predict the survival of $B C$ needed to be further explored.

To a certain degree, several limitations of this meta-analysis should not be ignored: Firstly, some published studies enrolled in this article did not conform to the HWE, leading to potential bias during genotypic errors or population selection; Secondly, the amount of included studies to explore the relation of TP53 codon 72 polymorphism with tumor stage or grade and smoking status were relatively small. Thus, these results need to be confirmed in more studies with larger sample sizes; Thirdly, adjusted estimates by some other covariances like age and gender could not be conducted in this meta-analysis; Fourthly, included studies all used retrospective study designs and they were less persuasive than perspective studies. Last but not least, BC was a multifactorial disease and persistent interactions between genetic and environmental factors, which might affect the occurrence and progression. The exploration of single gene region could not clarify the association of $\mathrm{BC}$ risk comprehensively. Accordingly, more attention should be devoted to interactions of gene-gene and gene-environment in future large multi-centric studies.

\section{Conclusion}

In summary, our results shed light on that TP53 codon 72 polymorphism was significantly associated with the susceptibility of BC in Asians, but not in Caucasians. Besides, positive associations were also revealed between this polymorphism and tumor stage/smoking status in BC cases. Based on the positive findings, we hypothesized that long-term exposure to smoking might lead to escalating possibility of a G>C mutation. Nevertheless, due to aforementioned limits, larger-sample with higher-quality and multi-centric studies were required to clarify these points.

\section{Acknowledgements}

\section{Role of the funding source}

This article was funded by the National Natural Science Foundation of China [grant number: 81501245; 81871151].

\section{Author Contributions}

NH.S, JD.X: Protocol/project development; XH.M, YM.W, R.C: Data collection or management; ZQ.Q, R.L, CJ.J: Data analysis; L.Z, Y.W: Manuscript writing/editing.

\section{Competing Interests}

The authors have declared that no competing interest exists.

\section{References}

1. Siegel RL, Miller KD, Jemal A. Cancer statistics, 2018. CA Cancer J Clin. 2018; 68: 7-30.

2. Torre LA, Bray F, Siegel RL, Ferlay J, Lortet-Tieulent J, Jemal A. Global cancer statistics, 2012. CA Cancer J Clin. 2015; 65: 87-108.

3. Rota M, Bosetti C, Boccia S, Boffetta P, La Vecchia C. Occupational exposures to polycyclic aromatic hydrocarbons and respiratory and urinary tract cancers: an updated systematic review and a meta-analysis to 2014. Arch Toxicol. 2014; 88: 1479-90.

4. Burger M, Catto JW, Dalbagni G, Grossman HB, Herr H, Karakiewicz P, et al. Epidemiology and risk factors of urothelial bladder cancer. Eur Urol. 2013; 63: 234-41.

5. Wadhwa N, Mathew BB, Jatawa SK, Tiwari A. Genetic instability in urinary bladder cancer: An evolving hallmark. J Postgrad Med. 2013; 59: 284-8.

6. Parkin DM. The global burden of urinary bladder cancer. Scand J Urol Nephrol Suppl. 2008: 12-20.

7. Li Q, Tang T, Zhang P, Liu C, Pu Y, Zhang Y, et al. Correlation of IL-31 gene polymorphisms with susceptibility and clinical recurrence of bladder cancer. Fam Cancer. 2017.

8. Wu Y, Yang Y. Complex association between ERCC2 gene polymorphisms, gender, smoking and the susceptibility to bladder cancer: a meta-analysis. Tumour biology: the journal of the International Society for Oncodevelopmental Biology and Medicine. 2014; 35: 5245-57.

9. Kouidhi S, Rouissi K, Khedhiri S, Ouerhani S, Cherif M, Benammar-Elgaaied A. MTHFR gene polymorphisms and bladder cancer susceptibility: a meta-analysis including race, smoking status and tumour stage. Asian Pac J Cancer Prev. 2011; 12: 2227-32.

10. Xu T, Xu ZC, Zou Q, Yu B, Huang XE. P53 Arg72Pro polymorphism and bladder cancer risk--meta-analysis evidence for a link in Asians but not Caucasians. Asian Pac J Cancer Prev. 2012; 13: 2349-54.

11. Kruiswijk F, Labuschagne CF, Vousden KH. p53 in survival, death and metabolic health: a lifeguard with a licence to kill. Nat Rev Mol Cell Biol. 2015; 16: 393-405

12. $\mathrm{Xu} \mathrm{H}$, el-Gewely MR. P53-responsive genes and the potential for cancer diagnostics and therapeutics development. Biotechnol Annu Rev. 2001; 7: 131-64. 
13. Tong WM, Hande MP, Lansdorp PM, Wang ZQ. DNA strand break-sensing molecule poly(ADP-Ribose) polymerase cooperates with p53 in telomere function, chromosome stability, and tumor suppression. Mol Cell Biol. 2001; 21: 4046-54.

14. Brosh $\mathrm{R}$, Rotter $\mathrm{V}$. When mutants gain new powers: news from the mutant $\mathrm{p} 53$ field. Nature reviews Cancer. 2009; 9: 701-13.

15. Post SM, Quintas-Cardama A, Pant V, Iwakuma T, Hamir A, Jackson JG, et al. A high-frequency regulatory polymorphism in the p53 pathway accelerates tumor development. Cancer Cell. 2010; 18: 220-30.

16. Klug SJ, Ressing M, Koenig J, Abba MC, Agorastos T, Brenna SM, et al. TP53 codon 72 polymorphism and cervical cancer: a pooled analysis of individual data from 49 studies. Lancet Oncol. 2009; 10: 772-84.

17. Qiao $\mathrm{Q}, \mathrm{Hu} \mathrm{W}$. The association between TP53 Arg72Pro polymorphism and lung cancer susceptibility: evidence from 30,038 subjects. Lung. 2013; 191: 369-77.

18. Zhuo XL, Cai L, Xiang ZL, Zhuo WL, Wang Y, Zhang XY. TP53 codon 72 polymorphism contributes to nasopharyngeal cancer susceptibility: a meta-analysis. Arch Med Res. 2009; 40: 299-305.

19. Rebbani K, Marchio A, Ezzikouri S, Afifi R, Kandil M, Bahri O, et al. TP53 R72P polymorphism modulates DNA methylation in hepatocellular carcinoma. Mol Cancer. 2015: 14:74

20. Rogler A, Rogenhofer M, Borchardt A, Lunz JC, Knoell A, Hofstaedter F, et al. P53 codon 72 (Arg72Pro) polymorphism and prostate cancer risk: association between disease onset and proline genotype. Pathobiology : journal of immunopathology, molecular and cellular biology. 2011; 78: 193-200.

21. Lin HY, Huang CH, Yu TJ, Wu WJ, Yang MC, Lung FW. p53 codon 72 polymorphism as a progression index for bladder cancer. Oncology reports. 2012; 27: 1193-9.

22. Lin YC, Hour TC, Tsai YC, Huang SP, Wu WJ, Chen $\mathrm{CH}$, et al. Preliminary evidence of polymorphisms of cell cycle regulatory genes and their roles in urinary tract urothelial cancer susceptibility and prognosis in a Taiwan population. Urologic oncology. 2017; 35: 543.e7-.e16.

23. Elhawary NA, Nassir A, Saada H, Dannoun A, Qoqandi O, Alsharif A, et al. Combined Genetic Biomarkers Confer Susceptibility to Risk of Urothelial Bladder Carcinoma in a Saudi Population. Dis Markers. 2017; 2017: 1474560.

24. Avirmed S, Wang BS, Selenge B, Sanjaajamts A, Ganbat B, Erdenebileg U, et al. Association between MDM2-SNP309 and p53R72P polymorphisms and the risk of bladder cancer in the Mongolian population. Molecular and clinical oncology. 2017; 7: 412-20

25. Hosen MB, Salam MA, Islam MF, Hossain A, Hawlader MZ, Kabir Y. Association of TP53 gene polymorphisms with susceptibility of bladder cancer in Bangladeshi population. Tumour biology : the journal of the International Society for Oncodevelopmental Biology and Medicine. 2015; 36: 6369-74.

26. Pineda S, Milne RL, Calle ML, Rothman N, Lopez de Maturana E, Herranz J, et al. Genetic variation in the TP53 pathway and bladder cancer risk. a comprehensive analysis. PLoS One. 2014; 9: e89952.

27. Lin HY, Yang MC, Huang CH, Wu WJ, Yu TJ, Lung FW. Polymorphisms of TP53 are markers of bladder cancer vulnerability and prognosis. Urologic oncology. 2013; 31: 1231-41.

28. Lin HY, Huang CH, Yu TJ, Wu WJ, Yang MC, Lung FW. p53 codon 72 polymorphism was associated with vulnerability, progression, but not prognosis of bladder cancer in a Taiwanese population: an implication of structural equation modeling to manage the risks of bladder cancer. Urologia internationalis. 2011; 86: 355-60.

29. Santos LE, Guilhen AC, de Andrade RA, Sumi LG, Ward LS. The role of TP53 PRO47SER and ARG72PRO single nucleotide polymorphisms in the susceptibility to bladder cancer. Urologic oncology. 2011; 29: 291-4.

30. Zhang $R$, Chen $W$, Zhang $W$, Jiang $Q$, Liu $C$, Lin $Y$, et al. Genetic polymorphisms of p53 codon 72 and bladder cancer susceptibility: a hospital-based case-control study. Genet Test Mol Biomarkers. 2011; 15: 337-41.

31. Pandith AA, Shah ZA, Khan NP, Rasool R, Afroze D, Yousuf A, et al. Role of TP53 Arg72Pro polymorphism in urinary bladder cancer predisposition and predictive impact of proline related genotype in advanced tumors in an ethnic Kashmiri population. Cancer Genet Cytogenet. 2010; 203: 263-8.

32. Srivastava P, Jaiswal PK, Singh V, Mittal RD. Role of p53 gene polymorphism and bladder cancer predisposition in northern India. Cancer Biomark. 2010; 8: 21-8.

33. Chung CJ, Huang CJ, Pu YS, Su CT, Huang YK, Chen YT, et al. Polymorphisms in cell cycle regulatory genes, urinary arsenic profile and urothelial carcinoma. Toxicol Appl Pharmacol. 2008; 232: 203-9.

34. Ye Y, Yang H, Grossman HB, Dinney C, Wu X, Gu J. Genetic variants in cell cycle control pathway confer susceptibility to bladder cancer. Cancer. 2008; 112: 2467-74.

35. Horikawa $\mathrm{Y}$, Nadaoka J, Saito $\mathrm{M}$, Kumazawa T, Inoue T, Yuasa T, et al. Clinical implications of the MDM2 SNP309 and p53 Arg72Pro polymorphisms in transitional cell carcinoma of the bladder. Oncology reports. 2008; 20: 49-55.

36. Kuroda $\mathrm{Y}$, Tsukino $\mathrm{H}$, Nakao H, Imai H, Katoh T. p53 Codon 72 polymorphism and urothelial cancer risk. Cancer Lett. 2003: 189: 77-83.

37. Mabrouk I, Baccouche S, El-Abed R, Mokdad-Gargouri R, Mosbah A, Said S, et al. No evidence of correlation between p53 codon 72 polymorphism and risk of bladder or breast carcinoma in Tunisian patients. Annals of the New York Academy of Sciences. 2003; 1010: 764-70.
38. Soulitzis $\mathrm{N}$, Sourvinos $\mathrm{G}$, Dokianakis DN, Spandidos DA. p53 codon 72 polymorphism and its association with bladder cancer. Cancer Lett. 2002; 179: 175-83.

39. Toruner GA, Ucar A, Tez M, Cetinkaya M, Ozen H, Ozcelik T. P53 codon 72 polymorphism in bladder cancer--no evidence of association with increased risk or invasiveness. Urol Res. 2001; 29: 393-5.

40. Chen WC, Tsai FJ, Wu JY, Wu HC, Lu HF, Li CW. Distributions of p53 codon 72 polymorphism in bladder cancer--proline form is prominent in invasive tumor. Urol Res. 2000; 28: 293-6.

41. Biros E, Kalina I, Salagovic J, Habalova V, Hriv ak M, Valansky L. p53 single nucleotide polymorphisms and bladder cancer. Neoplasma. 2000; 47: 303-6.

42. Wu WJ, Kakehi Y, Habuchi T, Kinoshita H, Ogawa O, Terachi T, et al. Allelic frequency of p53 gene codon 72 polymorphism in urologic cancers. Jpn J Cancer Res. 1995; 86: 730-6.

43. Wang P, Ye D, Guo J, Liu F, Jiang H, Gong J, et al. Genetic score of multiple risk-associated single nucleotide polymorphisms is a marker for genetic susceptibility to bladder cancer. Genes, chromosomes \& cancer. 2014; 53: 98-105.

44. Basu S, Murphy ME. Genetic Modifiers of the p53 Pathway. Cold Spring Harb Perspect Med. 2016; 6: a026302.

45. Yang Z, Nie S, Zhu H, Wu X, Jia S, Luo Y, et al. Association of p53 Arg72Pro polymorphism with bladder cancer: a meta-analysis. Gene. 2013; 512: 408-13.

46. Sjalander A, Birgander R, Kivela A, Beckman G. p53 polymorphisms and haplotypes in different ethnic groups. Hum Hered. 1995; 45: 144-9.

47. Shi $\mathrm{H}$, Tan SJ, Zhong $\mathrm{H}, \mathrm{Hu} \mathrm{W}$, Levine A, Xiao CJ, et al. Winter temperature and UV are tightly linked to genetic changes in the p53 tumor suppressor pathway in Eastern Asia. Am J Hum Genet. 2009; 84: 534-41.

48. Murphy ME. Polymorphic variants in the p53 pathway. Cell Death Differ. 2006; 13: 916-20.

49. Basu S, Gnanapradeepan K, Barnoud T, Kung CP, Tavecchio M, Scott J, et al. Mutant p53 controls tumor metabolism and metastasis by regulating PGC-1alpha. Genes Dev. 2018; 32: 230-43.

50. Saikia BJ, Das M, Sharma SK, Sekhon GS, Zomawia E, Singh YM, et al. Association of a p53 codon 72 gene polymorphism with environmental factors and risk of lung cancer: a case control study in Mizoram and Manipur, a high incidence region in North East India. Asian Pac J Cancer Prev. 2014; 15: 10653-8.

51. Qvick A, Sorbe B, Helenius G, Karlsson MG, Lillsunde Larsson G. Does p53 codon 72 polymorphism have a prognostic value in carcinoma of the vulva and vagina? Medical oncology (Northwood, London, England). 2017; 34: 36.

52. Kung CP, Liu Q, Murphy ME. The codon 72 polymorphism of p53 influences cell fate following nutrient deprivation. Cancer Biol Ther. 2017; 18: 484-91.

53. Kumari A, Bahl C, Singh N, Behera D, Sharma S. Association of p53 codon 72 polymorphism and survival of North Indian lung cancer patients treated with platinum-based chemotherapy. Molecular biology reports. 2016; 43: 1383-94.

54. Zha Y, Gan P, Liu Q, Yao Q. TP53 Codon 72 Polymorphism Predicts Efficacy of Paclitaxel Plus Capecitabine Chemotherapy in Advanced Gastric Cancer Patients. Arch Med Res. 2016; 47: 13-8. 